\title{
Effects of cuticular waxes on permeation of fungicides azoxystrobin and chlorothalonil into apples
}

Jeong-In Hwang ${ }^{1}$ (D, Da-Rong Seok ${ }^{2}$ and Jang-Eok Kim²*

\begin{abstract}
Time-dependent permeation characteristics of two fungicides azoxystrobin and chlorothalonil into apples were investigated in the presence and absence of the cuticular waxes. Either apple samples which were subjected to waxremoving treatment or not (raw) were individually submerged in each dilution solution of the tested fungicides for a short time, and some of each submerged sample were then washed in running tap water. All apple samples were incubated under controlled conditions and collected sequentially after 1, 24, and $48 \mathrm{~h}$. The collected apple samples were divided into four tissue parts before fungicide residue analysis: peel, pulp-1, pulp-2, and pulp-3. Most residues of azoxystrobin (70.7-86.4\%) in apples were present in the peel, and the residual extents in the pulps increased by removal of cuticular waxes. By washing treatment, 52.3-69.2\% of azoxystrobin residues in raw apples were removed. Meanwhile, all chlorothalonil residues were determined in the peel of apples, and their concentrations slightly increased by wax removal. However, significant chlorothalonil residues (84.5-91.1\%) were removed by washing the apple surface. Results in this study may be extensively utilized as basic data to understand characteristics of cuticular permeation and translocation of fungicides applied on fruit crops.
\end{abstract}

Keywords: Apple, Azoxystrobin, Chlorothalonil, Cuticular wax, Permeation

\section{Introduction}

Residues of pesticides applied on crops can adhere to the surface and then permeate steadily into the flesh over time based on the following three-step process: sorption into epicuticular waxes, diffusion through cuticular membrane, and desorption into the apoplast and symplast of epidermal cells [1]. The epicuticle layer of crop surface is covered with aliphatic waxes consisting of aliphatic, triterpenoid, flavonoid, and phenolic compounds to prevent from losses of inner water and impacts by external force and xenobiotic [2]. The epicuticular waxes may facilitate the permeation of hydrophobic pesticides into the plant tissues, and surfactant ingredients contained in commercially available products of pesticides can promote such permeating interactions [3]. Numerous

\footnotetext{
*Correspondence: jekim@knu.ac.kr

${ }^{2}$ School of Applied Biosciences, College of Agriculture and Life Sciences,

Kyungpook National University, Daegu 41566, Republic of Korea

Full list of author information is available at the end of the article
}

relevant studies have been previously conducted $[1,4-6]$, but still little is known about the plant-permeating characteristics of pesticide residues in relation to effects of the epicuticular waxes [1].

Pesticides which are relatively smaller in molecular size and more hydrophobic can have a greater potential to pass through waxy epicuticle $[1,7]$. Physicochemical properties of pesticides can also affect the diffusive and advective transfer of the residues into deeper plant tissue parts $[1,6,8]$. Particularly, as pome fruits like apples are clearly distinguished between the waxy peel and the moisture-rich pulp (84\%) [9], the mobility of pesticide residues in the apples may vary before and after the permeation across the peel. A previous study reported that all residues of acetamiprid, ferbam, phosmet, and thiabendazole applied to post-harvest apples were retained only in the peel (60-160 $\mu \mathrm{m}$ of depth) [10]. However, other study showed that residues of insecticide acephate applied on apples were detected in the pulp at $>0.5 \mu \mathrm{g} \mathrm{g}^{-1}$, which is its maximum residue level [11]. 
Based on these previous results, it is required to understand the transfer and distribution characteristics of pesticide residues permeated into the pulp of apples.

Pesticide residues deposited on outer surfaces of plants can primarily dissipate by external environmental factors associated with microbial activity, light, rain, temperature, and wind [12-15]. Meanwhile, it is likely that the dissipation of residues permeated into plant tissues is attributed to internal factors such as hydrolysis by moisture in the flesh and metabolism by plant hormones and enzymes. Hence, pesticide residues present within plant tissues may not be easy to be removed using any of external treatment methods. Some studies showed that heating or frying food ingredients with water or oil could reduce significant amounts of pesticide residues $[16,17]$. However, as fruit crops like apples are routinely consumed in a fresh state, several limited methods such as washing and peeling can be employed for removing the pesticide residues [18]. Thus, for fresh edible fruits, removal efficiencies of pesticide residues using washing and/or peeling treatments should be previously evaluated to consume them safely.

Fungicides azoxystrobin and chlorothalonil are largely used to control pathogenic fungi in apples and are commercially manufactured in a wettable powder formulation, containing different active ingredients of $10 \%$ and $75 \%$, respectively [19]. Physicochemical properties of azoxystrobin and chlorothalonil are different in molecular weight (403.4 and $265.9 \mathrm{~g} \mathrm{~mol}^{-1}$, respectively) and solubility in water $\left(6.7\right.$ and $0.81 \mathrm{mg} \mathrm{L}^{-1}$, respectively).
These differences between the fungicides may result in their different affinities with aliphatic cuticular waxes of crop surfaces and further contribute to describing different plant permeation trends between the fungicides. Based on results of pesticide residue monitoring study performed by Korean Ministry of Food and Drug Safety [20], azoxystrobin and chlorothalonil were included in a group of pesticides, violating frequently the acceptable residue criteria of pesticides for agricultural products.

In this study, based on a high sensitive analysis method using liquid chromatography-mass spectrometry, timedependent permeation and distribution characteristics of two fungicides azoxystrobin and chlorothalonil in apples was investigated in the presence and absence of the epicuticular waxes. Additionally, removal efficiencies of the fungicide residues from apples by washing and/or peeling treatments were evaluated.

\section{Materials and methods \\ Chemicals and reagents}

Analytical standards of fungicides, azoxystrobin (99.7\%) and chlorothalonil (99.5\%) were purchased from Dr. Ehrenstorfer $\mathrm{GmbH}$ (Augsbug, Germany) and Kureha Co. (Tokyo, Japan), respectively. Wettable powder-formulated products of azoxystrobin (10\%) and chlorothalonil (75\%) were purchased from Agrotech Co. Ltd. (Wanju, Korea) and Kyung Nong Co. Ltd. (Daegu, Korea), respectively. Physicochemical properties of the fungicides are shown in Table 1. Acetone, acetonitrile, dichloromethane, chloroform, and $n$-hexane were purchased

Table 1 Molecular structures and physicochemical properties of azoxystrobin and chlorothalonil

\begin{tabular}{|c|c|c|}
\hline Chemical & Azoxystrobin & Chlorothalonil \\
\hline \multicolumn{3}{|l|}{ Structure } \\
\hline Chemical name & $\begin{array}{l}\text { Methyl (E)-2-\{2-[6-(2-cyanophenoxy) pyrimidin-4-yloxy]phenyl\}- } \\
\text { 3methoxy-acrylate }\end{array}$ & Tetrachloroisophthalonitrile \\
\hline Molecular weight & $403.4 \mathrm{~g} \mathrm{~mol}^{-1}$ & $265.9 \mathrm{~g} \mathrm{~mol}^{-1}$ \\
\hline Log $K_{\text {ow }}$ & $2.5\left(20^{\circ} \mathrm{C}\right)$ & $2.92\left(25^{\circ} \mathrm{C}\right)$ \\
\hline Vapor pressure & $1.1 \times 10^{-7} \mathrm{mPa}\left(20^{\circ} \mathrm{C}\right)$ & $0.076 \mathrm{mPa}\left(25^{\circ} \mathrm{C}\right)$ \\
\hline Solubility & $\begin{array}{l}\text { In water } 6.7 \mathrm{mg} \mathrm{L}^{-1}\left(\mathrm{pH} 7,20^{\circ} \mathrm{C}\right) \\
\text { In hexane } 0.057, n \text {-octanol } 1.4 \text {, methanol } 20 \text {, toluene } 55 \text {, acetone } \\
86 \text {, ethyl acetate } 130 \text {, acetonitrile } 340 \text {, dichloromethane } 400 \text { (all } \\
\text { in } \mathrm{g} \mathrm{L}^{-1}, 20^{\circ} \mathrm{C} \text { ) }\end{array}$ & $\begin{array}{l}\text { In water } 0.81 \mathrm{mg} \mathrm{L}^{-1}\left(25^{\circ} \mathrm{C}\right) \\
\text { In acetone } 20.9,1,2 \text {-dichlorethane } 22.4 \text {, ethyl acetate } 13.8 \text {, } \\
\text { n-heptane } 0.2, \text { methanol } 1.7 \text {, xylene } 74.4 \text { in } \mathrm{L}^{-1}\end{array}$ \\
\hline Stability & $\mathrm{DT}_{50}$ 8.7-13.9 days at $\mathrm{pH} 7$ for aqueous photolysis & $\begin{array}{l}\text { Thermally stable at ambient temperatures. Stable to UV light in } \\
\text { aqueous media and in crystalline state. Stable in acidic and } \\
\text { moderately alkaline aqueous solutions; slow hydrolysis at } \\
\text { pH }>9\end{array}$ \\
\hline
\end{tabular}


from Burdick \& Jackson Inc. (Muskegon, MI, USA). Florisil (F0127, 60-100 mesh) was purchased from SigmaAldrich Chemical Co. (St. Louis, MO, USA), and sodium chloride and anhydrous sodium sulfate were purchased from Junsei Chemical Co. Ltd. (Tokyo, Japan).

\section{Cuticular wax removal from apples}

Apples of Fuji cultivar were purchased from an organic food market. Before experiments, all apples were washed well in running tap water with use of a kitchen detergent, and then moisture on the surface of apples was completely removed. Fifty apples were subjected to the removal of the cuticular waxes based on the wax extraction method reported in previous studies [5, 21]. Briefly, a pre-weighed apple was sonicated with $1 \mathrm{~L}$ of chloroform for 3 min using an ultrasonic bath Bransonic $^{\circledR}$ CPX8800H-E, Branson Ultrasonics Corp., Danbury, CT, USA), after which exactly $500 \mathrm{~mL}$ of the extract was taken into a round bottom flask pre-weighed. The extract in the flask was completely evaporated in a $40{ }^{\circ} \mathrm{C}$ water bath using a rotary vacuum evaporator (Laborota-4000, Heidolph Instrument GmbH \& Co., Germany), and the final weight of flask was recorded. The wax contents in apples were calculated using Eq. 1.

$$
\text { Wax content }(\%)=\left[W_{\mathrm{F}, \text { flask }}-W_{\mathrm{I}, \text { flask }}\right] / W_{\text {apple }} \times 2 \times 100
$$

where $W_{\mathrm{F}, \text { flask }}$ and $W_{\mathrm{I}, \text { flask }}$ indicate weights $(\mathrm{g})$ of flasks at final and initial times, respectively, and $W_{\text {apple }}$ is the weight (g) of apple before the wax removal treatment. Morphological changes of the apple surfaces before and after the wax removal were visualized using a field emission-scanning electron microscopy (FE-SEM; Hitachi S-4300 and EDX-350, Hitachi Instrument Inc., Tokyo, Japan) with platinum plating. Prior to the FE-SEM analysis, peels of wax removal-treated (WRT) and raw (nonWRT) apples were individually cut into small slices of $1 \mathrm{~mm}$ thickness using a razor blade, and they were then completely dried for 2 days using a freeze dryer (PVTFD 20R, IlsinBioBase Co. Ltd., Yangju, Korea).

\section{Fungicide permeation experiment}

Based on the pesticide's safe use guideline [19], commercial products of azoxystrobin (1 g) and chlorothalonil $(1.66 \mathrm{~g})$ were diluted in $1 \mathrm{~L}$ of water to achieve dilutions of 1000 and 600 times, respectively, and the diluted fungicide solutions were used for the permeation experiment. All permeation experiments were conducted using a modified version of the method suggested by Brown and Dezman (1990) [4]. The raw and WRT apples ( $n=24$ for each) were individually submerged in each of diluted fungicide solution for $15 \mathrm{~s}$ and dried in a hood at ambient temperature for $1 \mathrm{~h}$. The dried apples were incubated in an incubator
(JSPG-1500C, JS Research Inc., Republic of Korea) set as $25 \pm 2{ }^{\circ} \mathrm{C}, 75 \pm 5 \%$ humidity, and dark. Six apple samples from each of non-WRT and WRT groups were collected 1 , 24 , and $48 \mathrm{~h}$ after the incubation. Of six apple samples, 3 of each group were washed in running water for $20 \mathrm{~s}$, and the wet surfaces were slightly wiped with absorbable papers to remove moisture. Remaining three apples of each group were tested without washing treatment. A branched part which is at the edge of apple was removed, and the peel was carefully cut in a 1-mm thickness using a fruit peeler (Buybraand Inc., China). Subsequently, the apple pulp was divided into three parts by cutting in the direction from the outer surface to inner seeds: i.e. pulp-1, pulp-2, and pulp-3 (Additional file 1: Fig. S1). The thickness of each pulp part was $6 \mathrm{~mm}$, and the seeds were removed. The divided parts of each apple sample were individually weighed, homogenized using a grinder, and stored in a freezer at $-20{ }^{\circ} \mathrm{C}$ (GC-124HGFP, LG Electronics Inc., Republic of Korea) before fungicide residue analysis.

\section{Sample preparation and analysis}

Five grams of each of apple samples divided was weighed into a $50-\mathrm{mL}$ polytetrafluoroethylene tube, including $10 \mathrm{~mL}$ of water, $10 \mathrm{~mL}$ of acetonitrile, and $3 \mathrm{~g}$ of sodium chloride. The tube was shaken at $2500 \mathrm{rpm}$ for $15 \mathrm{~min}$ using a multi-tube vortex mixer (Henry Troemner LLC, NJ, USA) and centrifuged at $3000 \mathrm{rpm}$ for $5 \mathrm{~min}$ using a $40 \mathrm{~mL}$ centrifuging rotor (MF300, Hanil Science Industrial, Korea). A 5-mL aliquot of centrifuged supernatant (acetonitrile fraction) was evaporated in a $40{ }^{\circ} \mathrm{C}$ water bath using a vacuum evaporator and then dissolved in $1 \mathrm{~mL}$ of acetonitrile. A $5-\mu \mathrm{L}$ aliquot of the final sample solution was injected into analytical instruments. Azoxystrobin residues were analyzed using ultra-high performance liquid chromatography-tandem mass spectrometer (UHPLC-MS/MS; Shimadzu LC-MS 8030 with Nexera UFLC, Kyoto, Japan), equipped with a Hypercarb column $[100 \mathrm{~mm}$ (L.) $\times 2.1 \mathrm{~mm}$ (I.D.), $3 \mu \mathrm{m}$, Thermo Fisher Scientific, MA, USA]. Meanwhile, the analytical instrument for chlorothalonil was UHPLC-ultraviolet detector (UHPLC-UVD; Shimadzu Nexera UFLC, Kyoto, Japan), equipped with an ACE 3 Excel C18 column [150 mm (L.) $\times 2.1 \mathrm{~mm}$ (I.D.), $2 \mu \mathrm{m}$, Advanced Chromatography Technologies Ltd., Aberdeen, Scotland]. Residual concentrations of chlorothaolonil in samples were calculated using general solvent-based calibration methods, while the azoxystrobin concentrations were calculated using matrix-matched calibration (MMC) methods. The analytical residue concentrations of fungicides were recalculated with respect to their percent distribution extents in each tissue sample of apples using the respective weights of divided tissue parts of apples collected at each sampling time. 


\section{Instrumental conditions}

For azoxystrobin analysis, the isocratic mobile phase of UHPLC system was $70 \%$ acetonitrile in water (v/v) set at a flow rate of $0.3 \mathrm{~mL} \mathrm{~min}{ }^{-1}$, and the ionization mode of mass spectrometry system was electrospray ionization (ESI) mode. Flow rates of nebulizing and drying gases $\left(\mathrm{N}_{2}\right)$ were 3.0 and $15 \mathrm{~L} \mathrm{~min}^{-1}$, respectively, and the pressure of collision-induced dissociation gas (Ar) was $230 \mathrm{kPa}$. A temperature of desolvation line was $250{ }^{\circ} \mathrm{C}$. Mass spectra of azoxystrobin were obtained based on mass values of precursor and product ions analyzed in positive Q3 scanning mode. For the multiple reaction monitoring (MRM) analysis, a precursor ion of azoxystrobin was $\mathrm{m} / \mathrm{z} 403.8$, and the product ions were $\mathrm{m} / \mathrm{z} 344.1$ and 372.1. Dwell time and collision cell energy were set as $100 \mathrm{~ms}$ and $-15 \mathrm{~V}$, respectively, and pre bias voltages of Q1 and Q3 were -21 and $-19 \mathrm{~V}$, respectively. Meantime, for UHPLC-UVD analysis of chlorothalonil, the mobile phase was $70 \%$ acetonitrile in water $(\mathrm{v} / \mathrm{v})$ set at the rate of $3.0 \mathrm{~mL} \mathrm{~min}^{-1}$ in an isocratic mode, and a wavelength of the detector was $233 \mathrm{~nm}$.

\section{Quality control}

For recovery tests, $5 \mathrm{~g}$ of each apple sample containing no fungicide residues (i.e. blank samples) were spiked with individual standard solutions of azoxystrobin and chlorothalonil at known concentrations of 0.02 and $0.10 \mu \mathrm{g} \mathrm{g}^{-1}$. The spiked samples were analyzed in triplicate using the same analysis methods as previously described. Blank samples that did not spiked with fungicides were also analyzed as control samples to ensure that no interfering substances to the fungicide analysis were present in matrices. Additional blank samples were prepared to make MMC standard solution series (0.005$\left.2.0 \mathrm{mg} \mathrm{L}^{-1}\right)$ for the quantitative analysis of azoxystrobin. The standard solution series $\left(0.005-2.0 \mathrm{mg} \mathrm{L}^{-1}\right)$ of chlorothalonil for the solvent-based calibration were prepared in acetonitrile. The calibration standard solution series were analyzed for each test based on a blanket calibration method putting the analysis sequences of calibration solutions at both front and back ends of sample analysis sequences. Limits of quantification (LOQs, $\mathrm{ng} \mathrm{g}^{-1}$ ) of fungicides in apple samples were calculated based on the minimum detectable amount (MDA, ng) (Eq. 2).

$$
\mathrm{LOQ}=\mathrm{MDA} \times V_{\text {final }} / V_{\text {inject }} \times F_{\text {dilution }} \times 1000 / M_{\text {sample }}
$$

where $V_{\text {final }}(\mathrm{mL})$ is the final sample solution volume, and $V_{\text {inject }}(\mu \mathrm{L})$ is the sample injection volume. $F_{\text {dilu- }}$ tion (no unit) and $M_{\text {sample }}(\mathrm{g})$ indicate the dilution factor during the analysis process and the used sample amount, respectively.

\section{Permeation potential and removal efficiency}

The permeation potential (PP) of fungicides into pulp parts of apple was evaluated using Eq. 3.

$$
\mathrm{PP}(\%)=M_{\text {pulp }} / M_{\text {whole }} \times 100
$$

where $M_{\text {pulp }}$ and $M_{\text {whole }}$ are absolute amounts (ng) of fungicides in the pulp (sum of pulp-1, -2, and -3) and in whole apple body, respectively. The removal efficiency (RE) of fungicides from apples by washing treatment was calculated using Eq. 4.

$$
\operatorname{RE}(\%)=\left(M_{\text {before }}-M_{\text {after }}\right) / M_{\text {before }} \times 100
$$

where $M_{\text {before }}$ and $M_{\text {after }}$ mean the absolute amounts (ng) of fungicides in apples before and after washing treatment, respectively.

\section{Results and discussion}

\section{Quality control for fungicide analysis method}

The product ions of azoxystrobin analyzed using LC-MS. MS with a precursor ion of $\mathrm{m} / \mathrm{z} 403.8\left([\mathrm{M}+\mathrm{H}]^{+}\right)$were $\mathrm{m} / \mathrm{z} 344.1$ and 372.1 that might be produced by the cleavages of methyl formate moiety $\left(\left[\mathrm{M}^{+}-\mathrm{OMe}-\mathrm{CO}\right]\right)$ and demethoxylation $\left(\left[\mathrm{M}^{+}-\mathrm{OMe}\right]\right)$, respectively (Additional file 1: Fig. S2). The mass spectral patterns of azoxystrobin are similar to results reported in other study [22]. Analytical chromatograms of azoxystrobin and chlorothalonil using respective analysis instruments show that there were no impurity peaks interfering the chemical analysis (Additional file 1: Fig. S3). The linearity of calibration curves was acceptable with correlation coefficients of $>0.999$, and the LOQs were properly low at $2.0 \mathrm{ng} \mathrm{g}^{-1}$ corresponding to MDA of $0.025 \mathrm{ng}$. Recoveries of azoxystrobin and chlorothalonil spiked to blank samples of peel and pulp at concentrations of 0.02 and $0.10 \mu \mathrm{g} \mathrm{g}^{-1}$ were good at $81.2-99.4 \%$, with relative standard deviations (RSD) $<9.8 \%$ (Table 2). Thus, the fungicide analysis method established in this study was amenable to determining the residue amounts of azoxystrobin and chlorothalonil from peel and pulp samples of apples.

\section{Removal of apple waxes}

Morphologic structures of surfaces of WRT and raw apples were visualized using the FM-SEM (Fig. 1). The surface of non-WRT apple had an uneven layer of wax polymers formed in the granule type, which is one of 12 types of wax crystalloids [23] (Fig. 1a). This irregular apple surface may be also attributed to strong adhesion of foreign materials and destruction of wax layers by microorganisms and atmospheric conditions, such 
Table 2 Recoveries of azoxystrobin and chlorothalonil in peel and pulp samples of apples

\begin{tabular}{llllll}
\hline Fungicide & $\begin{array}{l}\text { Treated level } \\
\left(\boldsymbol{\mu g ~ g}^{-\mathbf{1}}\right)\end{array}$ & $\begin{array}{l}\text { Recovery } \\
\mathbf{r a t e}^{\mathbf{a}} \\
(\%) \pm S D\end{array}$ & $\begin{array}{l}\text { MDA } \\
(\mathbf{n g})\end{array}$ & $\begin{array}{l}\text { LOQ } \\
\left.\mathbf{( n g ~ g}^{-\mathbf{1}}\right)\end{array}$ \\
\cline { 2 - 3 } Peel & Pulp & & & \\
\hline Azoxystrobin & 0.02 & $97.2 \pm 2.5$ & $95.5 \pm 6.4$ & 0.025 & 2.0 \\
& 0.10 & $92.1 \pm 6.5$ & $90.4 \pm 8.9$ & & \\
Chlorothalonil & 0.02 & $95.6 \pm 0.9$ & $90.6 \pm 0.8$ & 0.025 & 2.0 \\
& 0.10 & $92.6 \pm 2.1$ & $97.2 \pm 0.6$ & & \\
\hline
\end{tabular}

MDA minimum detectable amount, $L O Q$ limit of quantification

a Mean of triplication

as chill, heat, drought, and irradiation [23]. Contrarily, the surface of WRT apple was clean without any of wax residues (Fig. 1b), and this proves that the wax ingredient was clearly removed by the wax extraction method used in this study. A mean of wax contents in apples was $0.389 \pm 0.0027 \mathrm{~g}$ which accounts for approximately $0.14 \%$ of the mean weight of apples $(278 \pm 20.8 \mathrm{~g})$, and this wax content was similar to the value $(0.12 \%)$ reported in previous study [24].

\section{Inward permeation of fungicides}

In the preliminary experiments, each of initial and $48 \mathrm{~h}$-incubated samples of apples submerged in fungicide solutions were analyzed in triplicate for whole fruit bodies without division of tissues, and the analytical results were then compared to confirm the fungicide dissipation of during the incubation. The differences between analytical concentrations of fungicides in initial and 48 h-incubated samples were $<8.2 \%$, indicating that insignificant fungicide residues are dissipated during the 48-h incubation.
Based on residual results analyzed (Table 3), percent distribution trends of azoxystrobin and chlorothalonil in each tissues sample of apples are illustrated in Figs. 2 and 3. For raw apples which were not subjected to the wax removal treatment, the greatest residues of azoxystrobin (328.7-340.5 $\mathrm{ng} \mathrm{g}^{-1}$; 78.3-86.4\% to the absolute amount of total residues) were found in the peel throughout the experimental period (Fig. 2a). After $1 \mathrm{~h}$ of incubation, $13.6 \%$ of azoxystrobin residues $\left(7.9 \mathrm{ng} \mathrm{g}^{-1}\right)$ were observed in pulp-1, but no residues were found in deeper pulp parts. After $24 \mathrm{~h}$ of incubation, the distribution extent of azoxystrobin residues in the pulp-1 increased to $18.6-18.7 \%\left(11.7-12.1 \mathrm{ng} \mathrm{g}^{-1}\right)$, and approximately $3.0 \%$ (3.3 $\mathrm{ng} \mathrm{g}^{-1}$ ) of the residues was found in pulp-2. This distribution extent in the pulp-2 was consistently maintained over the experimental period, and the residual concentrations in all pulp-3 samples were below LOQ of $2.0 \mathrm{ng} \mathrm{g}^{-1}$. Overall results so far show a systemicity of azoxystrobin into deeper pulp tissues of apples (up to depth of $13 \mathrm{~mm}$ within $48 \mathrm{~h}$ ). The systemic uptake and transfer of azoxystrobin into plants are also confirmed in results of other study [25].

Residues of azoxystrobin also permeated into WRT apples. Although mean residual concentrations of azoxystrobin in initially-collected samples were similar between raw and WRT apples, the concentrations in each divided sample of WRT apples increased consistently over time: $346.1-441.7 \mathrm{ng} \mathrm{g}^{-1}$ in the peel, 20.9$24.6 \mathrm{ng} \mathrm{g}^{-1}$ in the pulp-1, and $<2.0 \mathrm{ng} \mathrm{g}^{-1}$ to $6.2 \mathrm{ng} \mathrm{g}^{-1}$ in the peel-2. These increases in concentrations might occur by shrink and weight-loosen tissues of apples, resulting from a consistent loss of internal moisture by a weakened water-retaining function after cuticular wax removal treatment [2]. Compared to results in raw apples, residual concentrations of azoxystrobin permeated into the pulp were 1.8-2.6 times higher in WRT
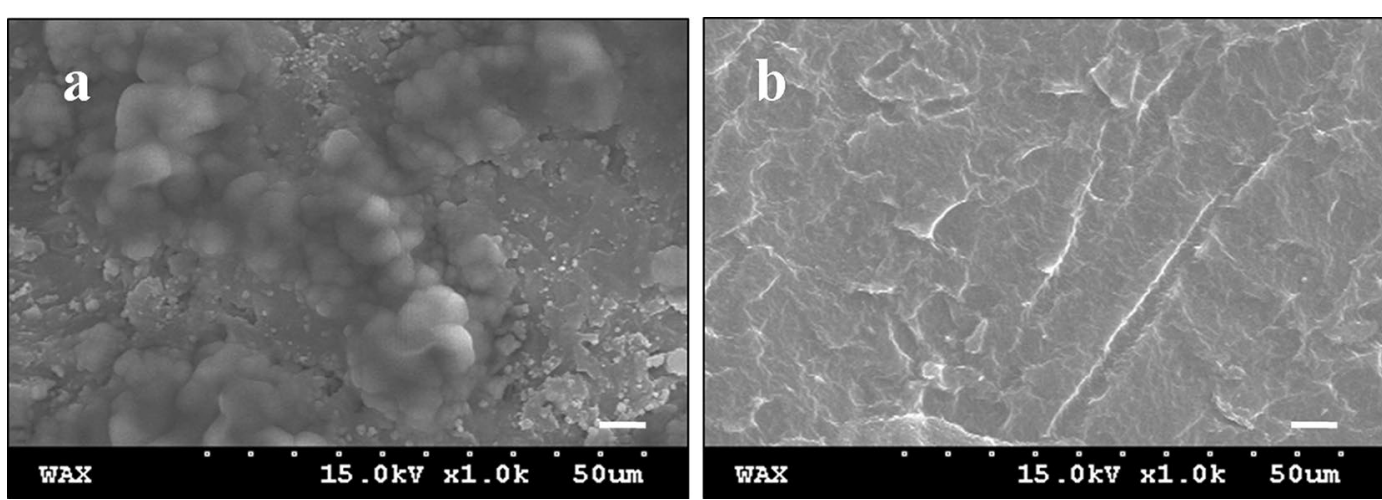

Fig. 1 Field emission-scanning electron microscopy (FE-SEM) images on surfaces of raw (a) and wax-removed (b) apples (lens magnification $=\times 1000$; scale bar $=50 \mu \mathrm{m}$ ) 
Table 3 Residual concentrations of azoxystrobin and chlorothalonil in each divided tissue sample of raw and wax removal-treated (WRT) apples after submerging in diluted solutions of fungicide

\begin{tabular}{|c|c|c|c|c|c|c|c|c|}
\hline \multirow[t]{3}{*}{ Fungicide } & \multirow{3}{*}{$\begin{array}{l}\text { Washing } \\
\text { treatment }\end{array}$} & \multirow[t]{3}{*}{ Apple part } & \multicolumn{6}{|c|}{ Residual concentration ${ }^{\mathrm{a}}\left(\mathrm{ng} \mathrm{g}^{-1}\right)$} \\
\hline & & & \multicolumn{2}{|c|}{ Incubation for $1 \mathrm{~h}$} & \multicolumn{2}{|c|}{ Incubation for $24 \mathrm{~h}$} & \multicolumn{2}{|c|}{ Incubation for $48 \mathrm{~h}$} \\
\hline & & & Raw & WRT & Raw & WRT & Raw & WRT \\
\hline \multirow[t]{8}{*}{ Azoxystrobin } & No & Peel & $336.0 \pm 5.2$ & $346.1 \pm 0.5$ & $328.7 \pm 0.9$ & $400.0 \pm 0.5$ & $340.5 \pm 0.4$ & $441.7 \pm 0.9$ \\
\hline & & Pulp-1 & $7.9 \pm 0.2$ & $20.9 \pm 0.0$ & $11.7 \pm 0.0$ & $22.4 \pm 0.1$ & $12.1 \pm 0.0$ & $24.6 \pm 0.0$ \\
\hline & & Pulp-2 & $<\mathrm{LOQ}$ & $<L O Q$ & $3.3 \pm 0.0$ & $4.3 \pm 0.0$ & $3.7 \pm 0.0$ & $6.2 \pm 0.0$ \\
\hline & & Pulp-3 & $<L O Q$ & $<L O Q$ & $<L O Q$ & $<L O Q$ & $<\mathrm{LOQ}$ & $<$ LOQ \\
\hline & Yes & Peel & $63.5 \pm 0.3$ & $29.6 \pm 0.6$ & $72.4 \pm 0.1$ & $40.6 \pm 0.6$ & $103.1 \pm 0.9$ & $52.0 \pm 0.6$ \\
\hline & & Pulp-1 & $8.4 \pm 0.0$ & $4.2 \pm 0.1$ & $12.7 \pm 0.1$ & $4.9 \pm 0.1$ & $14.2 \pm 0.2$ & $13.3 \pm 0.1$ \\
\hline & & Pulp-2 & $<\mathrm{LOQ}$ & $<\mathrm{LOQ}$ & $<L O Q$ & $<\mathrm{LOQ}$ & $2.5 \pm 0.0$ & $3.1 \pm 0.0$ \\
\hline & & Pulp-3 & $<L O Q$ & $<\mathrm{LOQ}$ & $<\mathrm{LOQ}$ & $<$ LOQ & $<\mathrm{LOQ}$ & $<$ LOQ \\
\hline \multirow[t]{8}{*}{ Chlorothalonil } & No & Peel & $421.4 \pm 0.4$ & $446.6 \pm 0.9$ & $407.3 \pm 0.3$ & $498.6 \pm 0.0$ & $407.3 \pm 0.6$ & $581.0 \pm 0.3$ \\
\hline & & Pulp-1 & $<\mathrm{LOQ}$ & $<L O Q$ & $<\mathrm{LOQ}$ & $<$ LOQ & $<L O Q$ & $<L O Q$ \\
\hline & & Pulp-2 & $<L O Q$ & $<L O Q$ & $<\mathrm{LOQ}$ & $<$ LOQ & $<L O Q$ & $<$ LOQ \\
\hline & & Pulp-3 & $<\mathrm{LOQ}$ & $<\mathrm{LOQ}$ & $<\mathrm{LOQ}$ & $<$ LOQ & $<$ LOQ & $<$ LOQ \\
\hline & Yes & Peel & $37.5 \pm 0.0$ & $7.6 \pm 0.0$ & $39.6 \pm 0.0$ & $8.1 \pm 0.0$ & $63.2 \pm 0.0$ & $8.9 \pm 0.0$ \\
\hline & & Pulp-1 & $<\mathrm{LOQ}$ & $<\mathrm{LOQ}$ & $<\mathrm{LOQ}$ & $<\mathrm{LOQ}$ & $<\mathrm{LOQ}$ & $<L O Q$ \\
\hline & & Pulp-2 & $<\mathrm{LOQ}$ & $<\mathrm{LOQ}$ & $<\mathrm{LOQ}$ & $<\mathrm{LOQ}$ & $<\mathrm{LOQ}$ & $<\mathrm{LOQ}$ \\
\hline & & Pulp-3 & $<\mathrm{LOQ}$ & $<\mathrm{LOQ}$ & $<\mathrm{LOQ}$ & $<\mathrm{LOQ}$ & $<\mathrm{LOQ}$ & $<\mathrm{LOQ}$ \\
\hline
\end{tabular}

LOQ limit of quantification, $2.0 \mathrm{ng} \mathrm{g}^{-1}$

a Mean of triplication $\pm S D$

apples (Table 3). However, similar to the azoxystrobin distribution trends in raw apples, most of the residues were present in the peel (70.2-71.2\%), followed by pulp-1 (26.2-28.8\%), pulp-2 (2.8-3.6\%), and pulp-3 (not distributed) (Fig. 2b). Based on these results, the peel-pulp permeation potentials (PPs, \%) of azoxystrobin in WRT apples were $28.8-29.8 \%$, which were higher than the values (13.6-21.7\%) in raw apples (Table 4).

Residues of chlorothalonil which is a non-systemic chemical [26] were observed only in peel samples of apples regardless of the presence and absence of cuticular waxes (Fig. 2c, d). This non-systemic property of chlorothalonil had been also observed in other study that tested for foliar-sprayed tomatoes [27]. Moreover, similar to experimental results of azoxystrobin, residual concentrations of chlorothalonil in the peel of WRT apples increased slightly over time (446.6-581.0 $\mathrm{ng} \mathrm{g}^{-1}$ ). As mentioned above, the increase of chlorothalonil concentrations in the wax-removed peel may be attributed to the increase in weight-to-volume ratio of apples by the consistent loss of internal moisture during the incubation period. Actually, weights of WRT apples reduced slightly during the incubation (mean $278 \pm 20.8-214 \pm 18.2$ g; detailed data not shown).

Experimental results of azoxystrobin and chlorothalonil described so far could not show obvious effects of cuticular waxes on the permeation of fungicides into the pulp, even though the wax removal treatment contributed to increasing fungicide concentrations in apples by promoting losses of the internal moisture. To better verify such effects of cuticular waxes, some of collected apple samples were carefully washed with the use of detergent, and the fungicide residue concentrations were then analyzed for each divided tissue samples.

\section{Fungicide residues after washing treatment}

By washing treatment with running tap water, significant residues of tested fungicides were removed from all of apple samples. For raw apples, 52.3-69.2\% of azoxystrobin residues were washed out (Table 4). The azoxystrobin removal extents by washing treatment were similar or slightly lower than those extents observed for other food samples: $72.5 \%$ for tomatoes [28], $75 \%$ for grapes [29], and $45 \%$ for strawberries [30] and $63.7-100.0 \%$ for Chwinamul, spinach, and perilla leaf [31]. Most of the residues remaining in washed apples were present in the peel, at concentrations of $63.5-103.1 \mathrm{ng} \mathrm{g}^{-1}(46.0-53.0 \%)$ (Fig. 3a). These concentrations in the peel were 3.3-5.3 times less than those in unwashed apples. However, the azoxystrobin concentrations in pulp-1 (8.4-14.2 $\mathrm{ng} \mathrm{g}^{-1}$; $45.9-54.0 \%)$ and pulp-2 $\left(2.5 \mathrm{ng} \mathrm{g}^{-1} ; 4.4 \%\right)$ were similar before and after washing treatment. These results may show that some of azoxystrobin residues deposited on the surface of apples can remain in the irremovable 


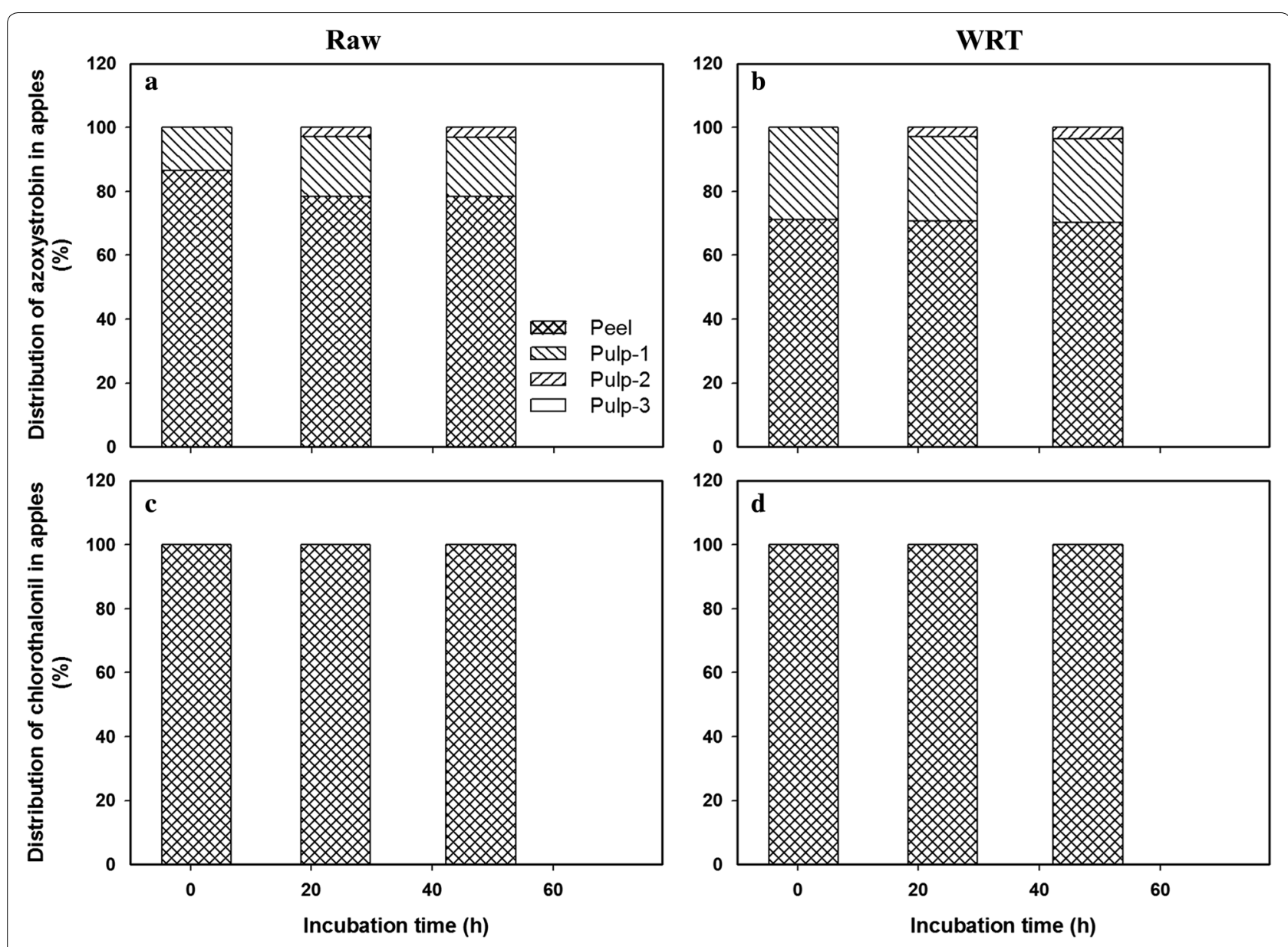

Fig. 2 Permeation and distribution trends of azoxystrobin $(\mathbf{a}, \mathbf{b})$ and chlorothalonil $(\mathbf{c}, \mathbf{d})$ deposited on/in raw $(\mathbf{a}, \mathbf{c})$ and wax removal-treated (WRT; b, d) apples during the 48-h incubation

state against the washing treatment, by being embedded in cuticular waxes and tissues. Adjuvants present in the commercial product of azoxystrobin also may affect the adhesion, cuticular permeation, and irremovable residue of active ingredients to the surface of apples [3, 32].

For WRT apples, 75.8-87.0\% of azoxystrobin residues were removed by washing treatment. Unlike the results for unwashed apples, the azoxystrobin concentrations in washed apples were lower in the wax-removed samples than in the samples that did not remove cuticular waxes. After washing treatment, azoxystrobin concentrations analyzed in the wax-removed peel were $29.6-52.0 \mathrm{ng} \mathrm{g}^{-1}$ (34.1-55.3\%), which were approximately 2 times smaller than those for raw apples (Fig. 3b). Moreover, the residual concentrations in the pulp of wax-removed apples were determined at 4.2-13.3 $\mathrm{ng} \mathrm{g}^{-1}$ (44.7-58.5\%) and $3.1 \mathrm{ng} \mathrm{g}^{-1}$ (7.4\%) for pulps-1 and -2 , respectively. These results indicate that a fraction of azoxystrobin residues in WRT apples could be reversibly released out from the tissues during the washing process.
The extents of chlorothalonil residues removed by washing treatment were $84.5-91.1 \%$ and $98.3-98.5 \%$ for raw and WRT apples, respectively (Fig. 3c, d). Similar to the results for azoxystrobin, larger chlorothalonil residues were washed out from WRT apples than from raw apples. All chlorothalonil residues after washing were detected in the peel samples (37.5-63.2 $\mathrm{ng} \mathrm{g}^{-1}$ and 7.6-8.9 $\mathrm{ng} \mathrm{g}^{-1}$ for raw and WRT apples, respectively), and this clearly shows non-systemicity of chlorothalonil. Fortunately, residues of chlorothalonil used on apples could be completely removed, if the apples were thoroughly washed in running water and then peeled. Previous study reported that $92 \%$ and $96.3 \%$ of chlorothalonil residues in the post-harvest apples could be removed by washing and peeling processes, respectively [27]. In this study, the residues of chlorothalonil observed in wax-removed peels of washed apples may be fractions of fungicides which were subjected to sorption and/or bound-residue interactions with cuticular tissues. 

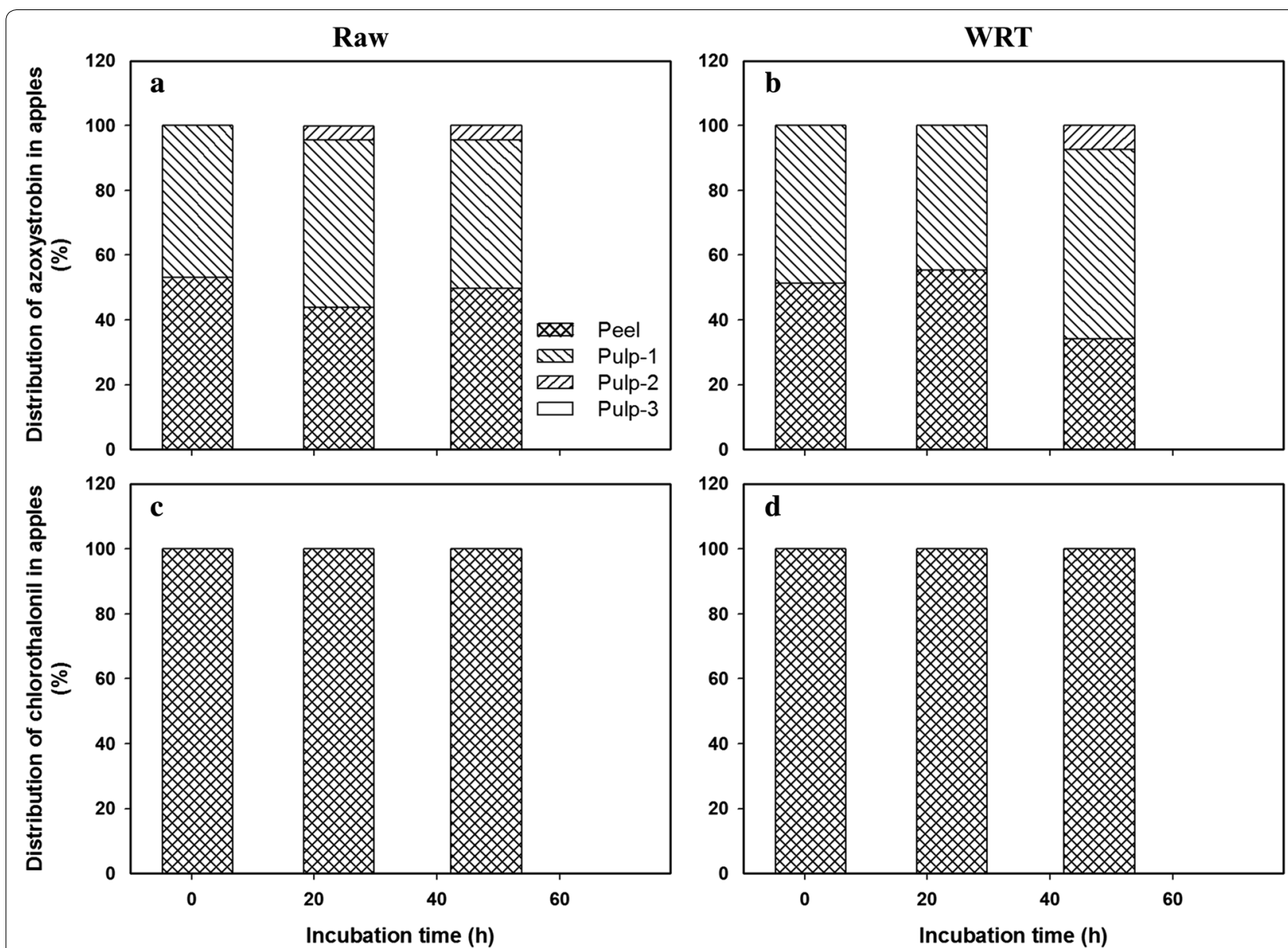

Fig. 3 Permeation and distribution trends of azoxystrobin $(\mathbf{a}, \mathbf{b})$ and chlorothalonil $(\mathbf{c}, \mathbf{d})$ in raw $(\mathbf{a}, \mathbf{c})$ and wax removal-treated (WRT; b, d) apples after washing treatment

Table 4 Permeation potentials of azoxystrobin and chlorothalonil into the pulp of apples and their removal efficiencies after washing treatment

\begin{tabular}{|c|c|c|c|c|c|}
\hline \multirow[t]{2}{*}{ Fungicide } & \multirow[t]{2}{*}{$\begin{array}{l}\text { Incubation } \\
\text { time (h) }\end{array}$} & \multicolumn{2}{|c|}{$\begin{array}{l}\text { Permeation } \\
\text { potential (\%) }\end{array}$} & \multicolumn{2}{|c|}{$\begin{array}{l}\text { Removal } \\
\text { efficiency (\%) }\end{array}$} \\
\hline & & Raw & WRT & Raw & WRT \\
\hline \multirow[t]{3}{*}{ Azoxystrobin } & 1 & 13.6 & 28.8 & 69.2 & 88.1 \\
\hline & 24 & 21.6 & 29.3 & 60.7 & 87.0 \\
\hline & 48 & 21.7 & 29.8 & 52.3 & 75.8 \\
\hline \multirow[t]{3}{*}{ Chlorothalonil } & 1 & 0.0 & 0.0 & 91.1 & 98.3 \\
\hline & 24 & 0.0 & 0.0 & 90.3 & 98.4 \\
\hline & 48 & 0.0 & 0.0 & 84.5 & 98.5 \\
\hline
\end{tabular}

WRT wax removal-treated apples

Overall results clearly show permeation characteristics of azoxystrobin inward apples and non-systemic properties of chlorothalonil against the apple permeation. The permeation characteristics of azoxystrobin may result in safety issues in apples. Our findings could be informative in understanding the cuticular permeation characteristics of pesticide deposited on the surfaces of crops as well as further in ensuring the safety of agricultural products from pesticide residues.

\section{Additional file}

Additional file 1: Figure S1. Schematic processes to divide apples collected from an incubator at each sampling time, into peel and pulp (pulp-1, -2, and -3) samples. Figure S2. Precursor ion-scanning chromatogram (a) and product ions' mass spectrum (b) of azoxystrobin analyzed by LC $-M S / M S$. Figure $\mathbf{S 3}$. Analytical chromatograms of azoxystrobin (a, $c, e)$ and chlorothalonil $(b, d, f)$ in apples analyzed using LC-MS/MS and UHPLC -UVD, respectively $\left(a, b=0.2 \mu \mathrm{gL}^{-1}\right.$ of fungicide standard solutions; $\mathrm{c}, \mathrm{d}=$ non-spiked apple controls; $\mathrm{e}, \mathrm{f}=$ apple samples spiked with fungicide at a concentration of $0.1 \mathrm{\mu g} \mathrm{g}^{-1}$ ).

Acknowledgements

Not applicable. 


\section{Authors' contributions}

JH was a major contributor in writing the manuscript and processing analytical data. DRS designed and performed the experiment associated with permeation of fungicides into apples. JEK, as a principle investigator, designed and led this research. All authors read and approved the final manuscript.

\section{Funding}

This work was supported by research grants from the Kyungpook National University, 2018 for experimental design and analysis; and from the National Research Foundation of Korea [NRF-2017R1A6A3A03008255] for data processing and manuscript writing.

\section{Availability of data and materials}

The datasets used and/or analysed during the current study are available from the corresponding author on reasonable request.

\section{Compliance with ethical standards}

\section{Competing interests}

The authors declare that they have no competing interests.

\section{Author details}

1 Soil and Water Sciences Department, University of Florida, Gainesville, FL 32611, USA. ${ }^{2}$ School of Applied Biosciences, College of Agriculture and Life Sciences, Kyungpook National University, Daegu 41566, Republic of Korea.

Received: 23 April 2019 Accepted: 20 June 2019

Published online: 30 June 2019

\section{References}

1. Li Y, Li Q, Chen B (2016) Organic pollutant penetration through fruit polyester skin: a modified three-compartment diffusion model. Sci Rep UK 6:23554

2. Riederer M, Schreiber $L$ (2001) Protecting against water loss: analysis of the barrier properties of plant cuticules. J Exp Bot 52:2023-2032

3. Zelená V, Veverka K (2007) Effect of surfactants and liquid fertilizers on transcuticular penetration of fungicides. Plant Prot Sci 43:151-156

4. Brown GE, Dezman DJ (1990) Uptake of imazalil by citrus fruit after postharvest application and the effect of residue distribution on sporulation of Penicillium digitatum. Plant Dis 74:927-930

5. Riccio R, Trevisan M, Capri E (2006) Effect of surface waxes on the persistence of chlorpyrifos-methyl in apples, strawberries and grapefruits. Food Addit Contam 23:683-692

6. Buchholz A (2006) Characterization of the diffusion of non-electrolytes across plant cuticles: properties of the lipophilic pathway. J Exp Bot 57:2501-2513

7. Baur P, Buchholz A, Schönherr J (1997) Diffusion in plant cuticles as affected by temperature and size of organic solutes: similarity and diversity among species. Plant Cell Environ 20:982-994

8. Fantke P, Juraske R (2013) Variability of pesticide dissipation half-lives in plants. Environ Sci Technol 47:3548-3562

9. Vesali F, Gharibkhani M, Komarizadeh MH (2011) An approach to estimate moisture content of apple with image processing method. Aust J Crop Sci 5:111-115

10. Yang T, Zhao B, Hou R, Zhang Z, Kinchla AJ, Clark JM, He L (2016) Evaluation of the penetration of multiple classes of pesticides in fresh produce using surface-enhanced raman scattering mapping. J Food Sci 81:T2891-T2901

11. Sanz-Asensio J, Martínez-Prado AP, Plaza-Medina M, Martínez-Soria MT, Pérez-Clavijo M (1999) Behaviour of acephate and its metabolite methamidophos in apple samples. Chromatographia 49:155-160

12. Goswami S, Vig K, Singh DK (2009) Biodegradation of $\alpha$ and $\beta$ endosulfan by Aspergillus sydoni. Chemosphere 75:883-888
13. Bajwa U, Sandhu KS (2014) Effect of handling and processing on pesticide residues in food-a review. J Food Sci Technol 51:201-220

14. Hammami H, Mohassel MGR, Parsa M, Bannayan-Aval M, Zand E, Hassanzadeh-Khayyat M, Nassirli H (2014) Photochemical behavior of sethoxydim in the presence of vegetable oils. J Agric Food Chem 62:6263-6268

15. Hwang Jl, Kim JE (2014) Residual patterns of acaricides, etoxazole and flufenoxuron in apples. Korean J Pestic Sci 18:61-68

16. Lee EH, Hwang JI, Kim JE (2015) Patterns of uptake and removal by processing types of triazole fungicides in onion. Korean J Pestic Sci 19:248-254

17. Lozowicka B, Jankowska M, Hrynko I, Kaczynski P (2016) Removal of 16 pesticide residues from strawberries by washing with tap and ozone water, ultrasonic cleaning and boiling. Environ Monit Assess 188:51

18. Han JL, Fang P, Xu XM, Li-Zheng XJ, Shen HT (2015) Study of the pesticides distribution in peel, pulp and paper bag and the safety of peat bagging. Food Control 54:338-346

19. Rural Development Administration (RDA) (2019) Service for agrochemical information. http://pis.rda.go.kr/. Accessed 28 Mar 2019

20. Ministry of Food and Drug Safety (MFDS) (2018) Food safety management guideline. http://www.mfds.go.kr/brd/m_218/view.do?seq=30894. Accessed 28 Mar 2019

21. McDonald RE, Nordby HE, McCollum TG (1993) Epicuticular wax morphology and composition are related to grapefruit chilling injury. HortScience 28:311-312

22. Parra J, Mercader JV, Agulló C, Abad-Somovilla A, Abad-Fuentes A (2012) Synthesis of azoxystrobin transformation products and selection of monoclonal antibodies for immunoassay development. Toxicol Lett 210:240-247

23. Barthlott W, Christoph N, Cutler D, Ditsch F, Meusel I, Theisen I, Wilhelmi H (1998) Classfication and terminology of plant epicuticular waxes. Bot J Linn Soc 126:237-260

24. Lurie S, Fallik E, Klein JD (1996) The effect of heat treatment on apple epicuticular wax and calcium uptake. Postharvest Biol Technol 8:271-277

25. Liu P, Wang H, Zhuo Y, Meng Q, Si N, Hao JJ, Liu X (2014) Evaluation of fungicides enestroburin and SYP1620 on their inhibitory activities to fungi and oomycetes and systemic translocation in plants. Pestic Biochem Physiol 112:19-25

26. Zhang Q, Saleem M, Wang C (2017) Probiotic strain Stenotrophomonas acidaminiphila BJ1 and reduces chlorothalonil toxicity to soil enzymes, microbial communities and plant roots. AMB Express 7:227

27. Kwon HY, Kim TK, Hong SM, Se EK, Cho NJ, Kyung KS (2015) Effect of household processing on pesticide residues in field-sprayed tomatoes. Food Sci and Biotechnol 24:1-6

28. Andrade GCRM, Monteiro SH, Francisco JG, Figueiredo LA, Rocha AA, Tornisielo VL (2015) Effect of types of washing and peeling in relation to pesticide residues in tomatoes. J Braz Chem Soc 26:1994-2002

29. Lentza-Rizos C, Avramides EJ, Kokkinaki K (2006) Residues of azoxystrobin from grapes to raisins. J Agric Food Chem 54:138-141

30. Angioni A, Schirra M, Garau VI, Melis M, Tuberoso CIG, Cabras P (2004) Residues of azoxystrobin, fenhexamid and pyrimethanil in strawberry following field treatments and the effect of domestic washing. Food Addit Contam 21:1065-1070

31. Yang A, Park JH, El-Aty AMA, Choi JH, Oh JH, Do JA, Kwon KS, Shim KH, Choi OJ, Shim JH (2012) Synergistic effect of washing and cooking on the removal of multi-classes of pesticides from various food samples. Food Control 28:99-105

32. Schereiber $L$ (2006) Review of sorption and diffusion of lipophilic molecules in cuticular waxes and the effects of accelerators on solute mobilities. J Exp Bot 57:2515-2523

\section{Publisher's Note}

Springer Nature remains neutral with regard to jurisdictional claims in published maps and institutional affiliations. 